\title{
The Early Development of the 2015/16 Quasi-Biennial Oscillation Disruption
}

\author{
PU LIN \\ Program in Atmospheric and Oceanic Sciences, Princeton University, Princeton, New Jersey \\ ISAAC HELD AND Yi MING \\ NOAA/Geophysical Fluid Dynamics Laboratory, Princeton, New Jersey
}

(Manuscript received 27 September 2018, in final form 9 January 2019)

\begin{abstract}
An unprecedented disruption of the quasi-biennial oscillation (QBO) started to develop from late 2015. The early development of this event is analyzed using the space-time spectra of eddies from reanalysis data. While the extratropical waves propagating horizontally into the tropics were assumed to be the main driver for the disruption, it was not clear why these waves dissipated near the jet core instead of near the jet edge as linear theory predicts. This study shows that the drastic deceleration of the equatorial jet was largely brought about by a single strong wave packet, and the local winds experienced by the wave packet served as a better indicator of the wave breaking latitude than the zonal mean winds. Surprisingly, tropical mixed Rossbygravity waves also made an appreciable contribution to the deceleration of the equatorial westerly jet by the horizontal eddy momentum fluxes, especially before January 2016. The horizontal eddy momentum fluxes associated with the tropical waves arise from the deformation of the wave structure when background westerlies increase with height. These horizontal eddy momentum anomalies from the tropical waves are commonly observed in the reanalysis data but are typically much weaker than those in the 2015/16 winter. The possibility exists that exceptionally strong equatorially trapped waves precondition the flow to disruption by an extratropical disturbance.
\end{abstract}

\section{Introduction}

The quasi-biennial oscillation (QBO) is the most prominent circulation pattern in the tropical stratosphere, featuring alternating easterlies and westerlies that slowly descend from the stratopause to the tropopause (Baldwin et al. 2001, and references therein). It is mainly driven by the vertically propagating waves with easterly and westerly phase speeds that dissipate in the corresponding shear zones, leading to easterly acceleration in easterly shear zones (where easterlies increases with height) and westerly acceleration in westerly shear zones (Holton and Lindzen 1972). These tropically trapped waves are of various horizontal scales, ranging from planetary scales to a few kilometers or less (e.g., Baldwin et al. 2001; Kim and Chun 2015). Since tropical stratospheric wind measurements became available in the 1950s, this oscillation in zonal wind has been observed consistently with a period around 28 months.

Corresponding author: Pu Lin, pulin@princeton.edu
However, this regularity was distorted in late 2015 when easterlies started to develop at the core of the westerly jet instead of in an easterly shear zone, and the descent of the zonal wind pattern halted and even reversed for a few months (Newman et al. 2016; Osprey et al. 2016). Momentum budget analyses show that the abnormal easterly acceleration during the 2015/16 boreal winter is mainly driven by the divergence of the eddy momentum flux $\overline{u^{\prime} v^{\prime}}$ (Osprey et al. 2016; Coy et al. 2017; Barton and McCormack 2017). Studies hence attributed the QBO disruption to the Northern Hemisphere extratropical Rossby waves that propagated horizontally into the tropical lower stratosphere and dissipated near the equator (Osprey et al. 2016; Coy et al. 2017; Barton and McCormack 2017). The smallscale gravity waves generally make appreciable contribution to the QBO forcing (e.g., Dunkerton 1997; Holt et al. 2016), but are shown to have little effect during the 2015/16 winter (Coy et al. 2017). By February 2016, a thin layer of easterlies was established near the level of $40 \mathrm{hPa}$. Once the easterlies developed inside the westerlies, the propagation pattern of both 
tropical and extratropical waves was altered, facilitating further disruption of the QBO (Hitchcock et al. 2018). The QBO seems to have returned to its normal cycle by the end of 2016.

Questions remain on how the easterly acceleration occurred at the westerly jet core. Linear wave theory predicts that a Rossby wave propagates when its phase speed is more easterly than the background wind, and dissipates close to the critical latitude where its phase speed matches with the background wind. In the case when a westerly jet is located near the equator, there is a westerly minimum at the subtropics that filters out the waves of strong westerly phase speed, and only those waves with easterly or weak westerly phase speed can penetrate into the tropics. Therefore, all waves reaching the equatorial westerly jet are of a phase speed that is more easterly than the jet itself, and minimal dissipation is expected to occur at the jet core from the linear theory. Based on a global shallowwater model, O'Sullivan (1997) showed that these extratropical Rossby waves can reduce the width of the equatorial westerly jet, but the jet-core strength remains undiminished even on seasonal time scales. Furthermore, anomalously strong eddy momentum flux emanating from extratropics into the tropics was also observed during the 1987/88 and 2010/11 winters (Coy et al. 2017). Yet no similar disruption of the QBO was found.

In this study, we address this puzzle by analyzing the space-time spectral characteristics and the detailed evolution of the eddy momentum flux. We focus on the period when the easterly anomalies started to develop, that is, the 2015/16 boreal winter. We find that the strong horizontal eddy momentum flux divergence observed near the equator during the 2015/16 winter was associated in large part with an episode of extratropical Rossby wave breaking as suggested by earlier studies (Newman et al. 2016; Osprey et al. 2016; Coy et al. 2017; Barton and McCormack 2017). But we also find that tropical mixed Rossby-gravity (MRG) wave contributed to the equatorial momentum flux divergence. We discuss the behavior of these two types of waves and explain how they each contributed to the westerly deceleration/easterly acceleration at the equatorial jet center. In particular, we contrast the 2015/16 winter with the 2010/11 winter, and we address why the QBO behaved differently in these two winters given comparable strong wave flux coming from the northern extratropics. In the following, we will first describe the dataset used and the analysis methodology in section 2 , and then we present the evolution of the zonal winds during the 2015/16 winter and discuss the effects of the extratropical and tropical waves in section 3 , followed by a summary and discussion in section 4.

\section{Data and method}

Our analysis is based on the ERA-Interim products output on its model levels (Dee et al. 2011). This QBO event has been analyzed using other reanalysis products (Newman et al. 2016; Coy et al. 2017; Barton and McCormack 2017), showing similar results compared to those using ERA-Interim (Osprey et al. 2016). Most results are shown on the $35.8-\mathrm{hPa}$ level, where the easterly acceleration are the strongest. The eddy fluxes $\overline{u^{\prime} v^{\prime}}, \overline{u^{\prime} w^{\prime}}$, and $\overline{v^{\prime} \theta^{\prime}}$ are calculated using the 6-hourlyresolution output, in which $u^{\prime}, v^{\prime}$, and $w^{\prime}$ are the eddy component of the zonal, meridional, and vertical winds, respectively; $\theta^{\prime}$ is the eddy component of the potential temperature; and overbar indicates the zonal average. Using these eddy fluxes, we calculate the EliassenPalm (EP) flux following Andrews et al. [1987, their Eq. (3.5.3)]. We pay special attention to the eddy momentum flux from the covariance between the zonal and meridional wind $\overline{u^{\prime} v^{\prime}}$ (horizontal eddy momentum flux) as studies have shown its importance in the momentum budget during the 2015/16 winter (Osprey et al. 2016; Coy et al. 2017; Barton and McCormack 2017). In this paper, we present the horizontal eddy momentum convergence $\left[-\partial\left(\overline{u^{\prime} v^{\prime}} \cos ^{2} \phi\right) /\left(a \cos ^{2} \phi \partial \phi\right)\right]$, so that it has the same sign as the zonal wind tendency, and its value is directly comparable to the zonal wind tendency, in which $a$ is the radius of Earth, and $\phi$ is latitude. We also consider the eddy momentum flux from the covariance between the zonal and vertical winds $\overline{u^{\prime} w^{\prime}}$ (vertical eddy momentum flux). The convergence of the vertical eddy momentum flux is defined as $-\left(1 / \rho_{0}\right) \partial\left(\overline{u^{\prime} w^{\prime}} \rho_{0}\right) / \partial z$, where $\rho_{0}$ is the reference density, and $z$ is the logpressure height.

We compute the space-time cross spectra (Hayashi 1971) and the angular phase speed spectra (Randel and Held 1991) for these eddies. To calculate the spectra in each month, we use 60 days of data starting from day 15 of the previous month. Each data chunk is tapered with a Hamming window to reduce the noise from sampling (von Storch and Zwiers 1999). Following Randel and Held (1991), the space-time cross spectra are then interpolated into the domain of angular phase speed and wavenumber, and the angular phase speed spectra are obtained by summing over wavenumbers.

We also filter the time series with a threshold frequency of 0.15 cycle per day (cpd) to examine the evolution due to high- and low-frequency waves. We apply the sixth-order Butterworth filter forward and 

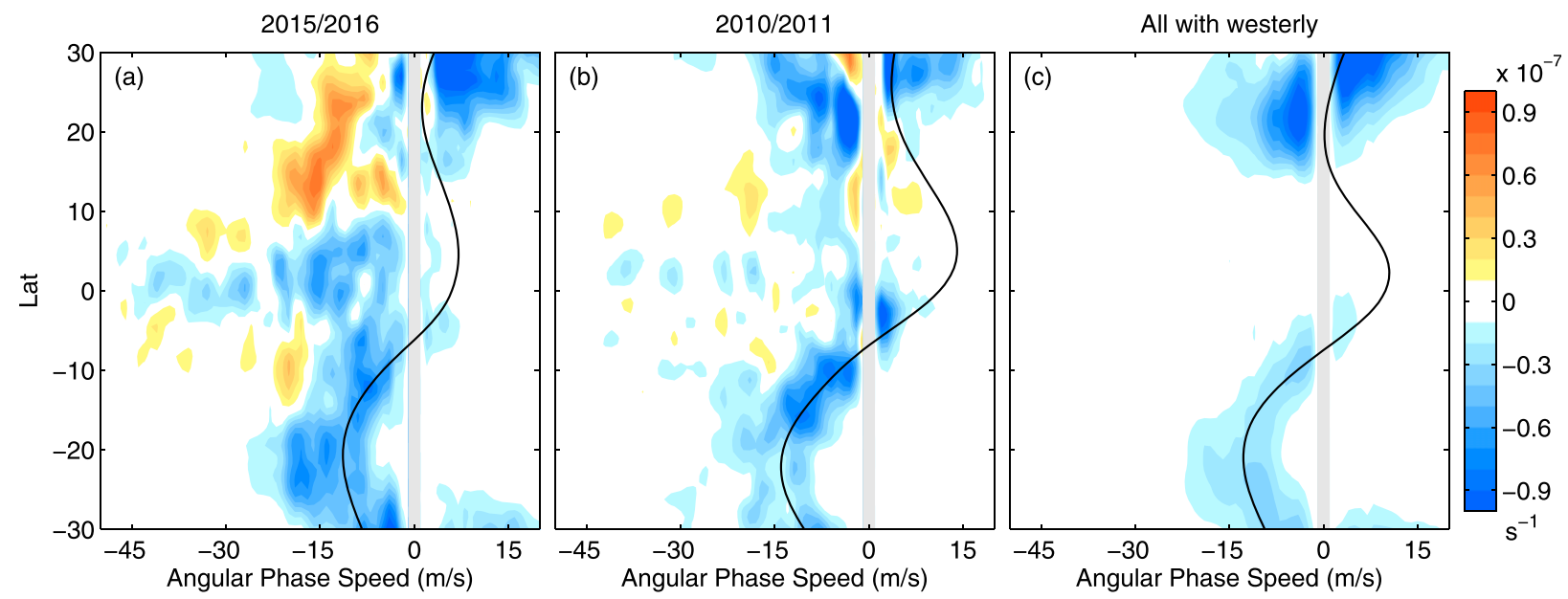

FIG. 1. Angular phase speed spectra for eddy momentum flux convergence (color shading) and background zonal wind $U / \cos \phi$ (black line) at $35.8 \mathrm{hPa}$ averaged over (a) November 2015-February 2016, (b) November 2010-February 2011, and (c) November-February for 17 boreal winters with equatorial westerlies (1980/81, 1982/83, 1985/86, 1987/88, 1988/89, 1990/91, 1992/93, 1994/95, 1997/98, 1999/2000, 2002/03, 2004/05, 2006/07, 2008/09, 2010/11, 2013/14, and 2015/16).

backward to the daily mean winds to avoid phase shift from the filtering. Daily mean instead of 6-hourly data is used so that irrelevant high-frequency signals are diminished. The first and last 10 days are discarded after filtering. Eddy momentum fluxes are then calculated using the low-passed and high-passed winds. Covariance between the low-frequency and highfrequency winds is found to be very small and hence is ignored.

\section{Results}

Figure 1 shows the angular phase speed spectra for eddy momentum flux convergence at $35.8 \mathrm{hPa}$ averaged from November to February for the 2015/16 winter, the 2010/11 winter, and all 17 boreal winters since 1979 that have westerlies at the equator. Wave activity is strong in the northern extratropics during boreal winters. As these waves propagate upward and equatorward, most of them will reach their critical lines and dissipate before reaching the tropics. But if there are westerlies in the tropics, those Rossby waves with easterly or weak westerly phase speed may propagate across the equator, and dissipate in the Southern Hemisphere. This is clearly seen in the phase speed spectra, which shows that $\overline{u^{\prime} v^{\prime}}$ diverges strongly along the background zonal wind in the Southern Hemisphere. During the 2015/16 winter, however, additional momentum divergence for waves of strong easterly phase speed was found between $5^{\circ} \mathrm{S}$ and $10^{\circ} \mathrm{N}$ where the zonal-mean zonal wind was still westerly. This differs from other winters with similar background winds, in which little divergence is found inside westerlies or away from the critical latitude. It is this additional divergence inside the westerlies that sets the 2015/16 winter apart from others.

Which waves caused this additional eddy momentum flux divergence during the 2015/16 winter? We seek hints in the space-time spectra. Figure 2 shows the averaged space-time spectra of EP flux divergence at the equator for the 2015/16 winter. Superimposed are theoretical dispersion lines for equatorial Kelvin and MRG waves for a set of equivalent depths as in Wheeler and Kiladis (1999). In addition, we calculate the dispersion relation for nondivergent barotropic Rossby wave at $40^{\circ} \mathrm{N}$ as $\omega=k \bar{u}-k \beta_{\text {eff }} /\left(k^{2}+l^{2}\right)$ following Abalos et al. (2016), in which $\omega$ is angular frequency, $k$ is zonal wavenumber, $l$ is local meridional wavenumber, and $\beta_{\mathrm{eff}}=\beta-u_{y y}$.

Westerly deceleration (indicated by the negative EP flux divergence) is found along these dispersion lines of extratropical Rossby waves, supporting the extratropical wave argument suggested in previous studies (e.g., Osprey et al. 2016; Coy et al. 2017). However, additional decelerations are found at the easterly phase speeds with higher frequencies, which lie along the theoretical dispersion lines of equatorial MRG waves. The spectra also show acceleration along theoretical dispersion lines of equatorial Kelvin waves.

Spectra are integrated separately across three frequency ranges: easterly waves with frequency $0<\omega<0.15 \mathrm{cpd}$, easterly waves with frequency $0.15 \leq \omega \leq 0.5 \mathrm{cpd}$, and westerly waves with frequency $0.05 \leq \omega \leq 0.5 \mathrm{cpd}$. The distinction among the three groups is apparent by their EP flux patterns as shown in Fig. 3. Most of the lowfrequency easterly waves originate from the Northern 


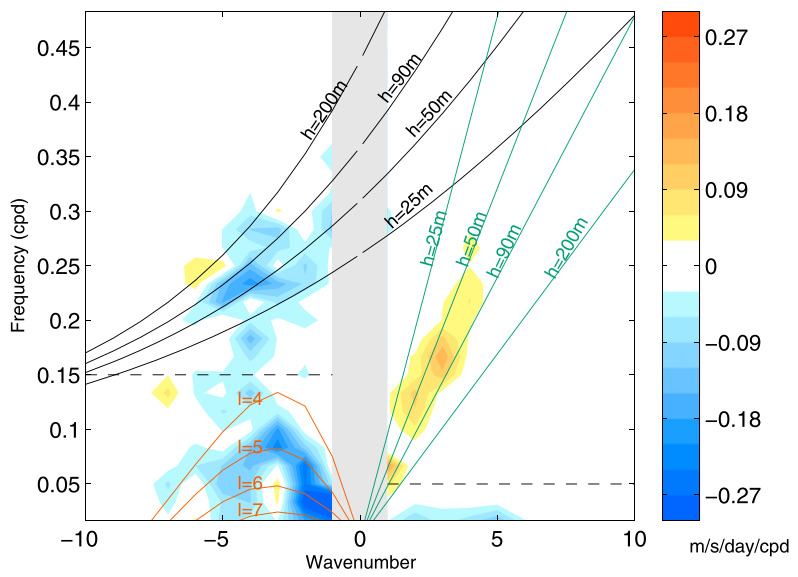

FIG. 2. Space-time spectrum for EP flux divergence at $35.8 \mathrm{hPa}$ averaged over $5^{\circ} \mathrm{S}-5^{\circ} \mathrm{N}$ from November 2015 to February 2016. Black dashed lines mark the boundary of the frequency ranges discussed in the text. Positive wavenumbers are for westerly waves, and negative wavenumbers are for easterly waves. Black solid lines plot the dispersion curves of the mixed Rossby-gravity wave and $n=0$ westerly inertial gravity wave for equivalent depth $h=25,50$, 90 , and $200 \mathrm{~m}$. Green solid lines plot the dispersion curves of Kelvin waves for equivalent depth $h=25,50,90$, and $200 \mathrm{~m}$. Orange solid lines plot the dispersion curves for extratropical Rossby waves for local meridional wavenumber $l=4-7$. See text for details of the dispersion curves.

Hemisphere midlatitudes and then propagate horizontally across the equator into the Southern Hemisphere (Fig. 3a). These waves generally cause westerly deceleration (easterly acceleration) of the mean flow. Weaker EP flux divergence is found near the equator where the westerly jet core resides. The EP flux from this frequency band is the strongest and is similar to the EP flux calculated from all waves shown in earlier studies (Osprey et al. 2016; Coy et al. 2017; Barton and McCormack 2017). The high-frequency easterly waves are largely confined within the tropics (Fig. 3b). Consistent with the expectation for equatorial MRG waves, upward EP flux is found on both sides of the equator. EP flux from this frequency band also points equatorward, leading to westerly deceleration at the equator and westerly acceleration off the equator. While the magnitudes (i.e., the length of EP flux vectors) of these high-frequency easterly waves are much weaker than the low-frequency ones, their effects on the equatorial mean flow (i.e., EP flux divergence) are comparable to the low-frequency waves. For both low-frequency and high-frequency easterly waves, the EP flux divergence in the tropics is mainly contributed by the divergence of the horizontal eddy momentum flux. The westerly waves show EP fluxes pointing downward in the tropics (Fig. 3c), consistent with the expectation for equatorial Kelvin waves. These waves lead to westerly acceleration in the tropics, with stronger acceleration in the lower stratosphere where the mean flow had a westerly shear.

Comparing the 2010/11 winter (Figs. 3d-f) with the 2015/16 winter (Figs. 3a-c), we find that the general propagation pattern of each wave group does not differ much between the two winters. The stronger westerly deceleration of the equatorial jet during the 2015/16 winter came from a strong deceleration centered around $35 \mathrm{hPa} 5^{\circ} \mathrm{N}$ from the low-frequency easterly waves that was absent in the 2010/11 winter, as well as the stronger horizontal EP fluxes from the highfrequency easterly waves.

Because the space-time spectra only measure the average wave characteristics over a certain temporal window and cannot resolve the finer evolution over time, we employ a temporal filter to differentiate different wave groups on finer time scales. Note that the temporal filter cannot separate between the easterly and westerly waves. But the zonal wind tendency from the westerly Kelvin waves is generally weaker than the easterly waves at $35 \mathrm{hPa}$, and mostly comes from the vertical momentum flux $\overline{u^{\prime} w^{\prime}}$ instead of the horizontal momentum flux $\overline{u^{\prime} v^{\prime}}$. We therefore consider the lowfrequency $(<0.15 \mathrm{cpd}) \overline{u^{\prime} v^{\prime}}$ as the contribution from the extratropical Rossby waves, the high-frequency $\overline{u^{\prime} v^{\prime}}$ as the contribution from the tropical MRG waves, and $\overline{u^{\prime} w^{\prime}}$ from all frequencies as the contribution from the tropical Kelvin waves. Since extratropical Rossby, tropical MRG, and Kelvin waves all have periods of a few days or longer, we apply the filter to daily mean instead of 6-hourly outputs to eliminate other irrelevant high-frequency variations such as solar tides. Figure 4 shows the zonal wind tendency as well as contributions from the three wave groups during the 2015/16 and 2010/11 winters. Consistent with earlier studies (Osprey et al. 2016; Coy et al. 2017; Barton and McCormack 2017), other contributions to the zonal wind tendency, such as additional terms in the EP flux divergence, advection by the mean circulation, and the reanalysis's unresolved processes, are found to be relatively small near the equatorial jet during the two winters and hence are not shown.

As expected, the dissipation of the extratropical Rossby waves is strongly modulated by the background zonal wind. In both winters, we see the low-frequency $\overline{u^{\prime} v^{\prime}}$ diverges strongly at the southern flank of the equatorial jet where there is strong horizontal shear. During the 2015/16 winter, the shear zone gradually moved northward, and the low-frequency momentum divergence followed this migration. In contrast, during the 2010/11 winter, the location of the shear zone had less fluctuation, and the low-frequency momentum 

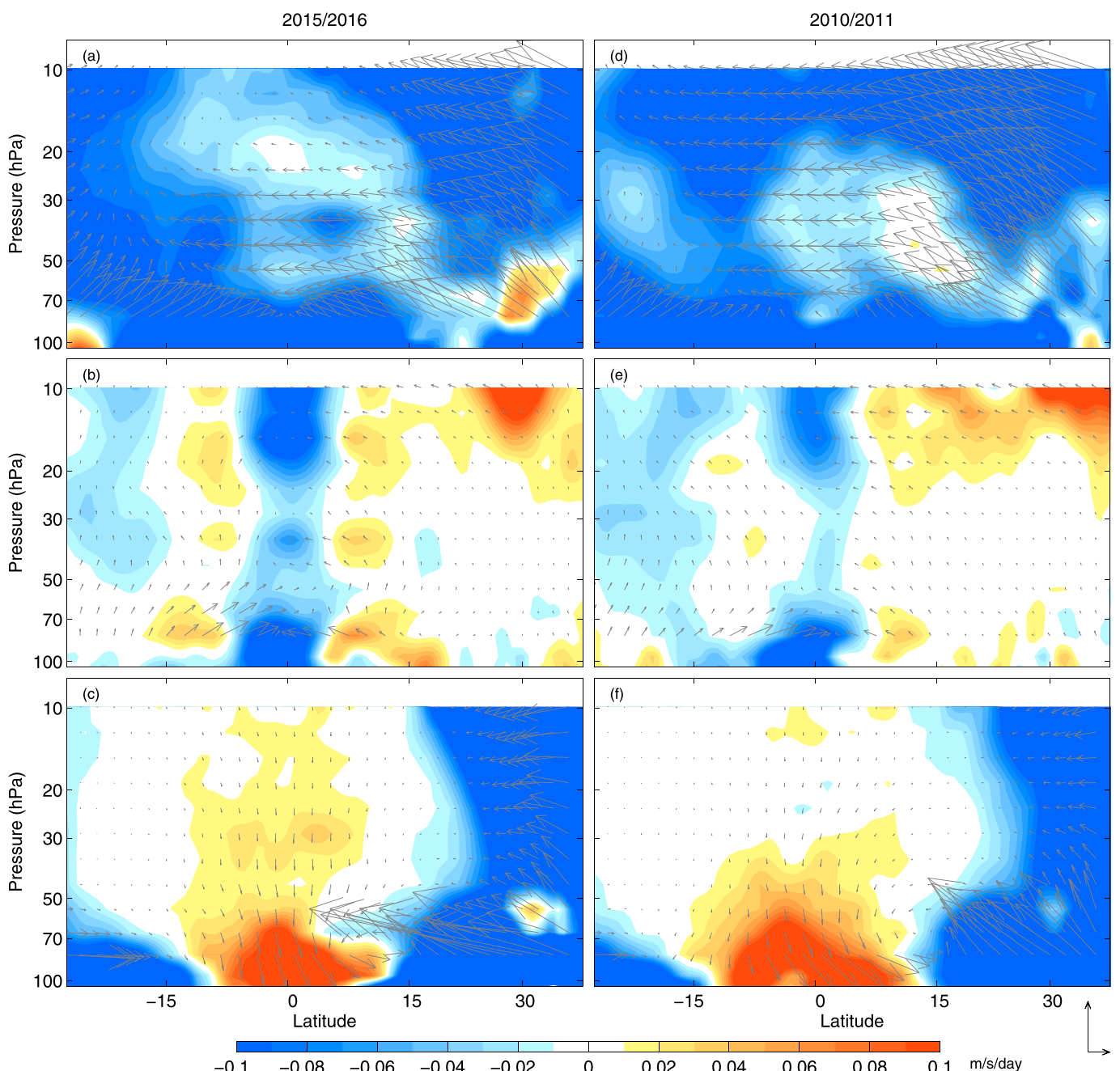

FIG. 3. EP flux (vectors) and its divergence (color shading) for (a),(d) waves with easterly phase speed and frequency lower than $0.15 \mathrm{cpd}$, (b),(e) waves with easterly phase speed and frequency between 0.15 and $0.5 \mathrm{cpd}$, and (c),(f) waves with westerly phase speed and frequency between 0.05 and $0.5 \mathrm{cpd}$. (a)-(c) Results averaged over November 2015-February 2016. (d)-(f) Results averaged over November 2010-February 2011. The reference arrows in the lower-right corner represent a vertical EP flux of $3 \times 10^{3} \mathrm{~kg} \mathrm{~s}^{-2}$ and a horizontal EP flux of $3 \times 10^{5} \mathrm{~kg} \mathrm{~s}^{-2}$.

divergence largely remained south of the equator. This pattern agrees qualitatively with the theory that Rossby waves dissipate at the critical latitude where its phase speed matches with the background wind.

There are occasional episodes in which the lowfrequency momentum divergence occurred away from the shear zone and inside the westerly jet. One exceptional example occurred around 1 February 2016 north of the equator, during which the divergence exceeded $0.4 \mathrm{~m} \mathrm{~s}^{-1} \mathrm{day}^{-1}$, and the background zonal wind quickly dropped from $>5 \mathrm{~m} \mathrm{~s}^{-1}$ to easterlies. Comparing Figs. 4b and 3a, we see that the tropical isolated peak of deceleration seen in the winteraveraged plot is almost entirely driven by this single episode. We will examine this episode in detail in the next subsection.

On the other hand, the tropical MRG waves show no horizontal displacement with the equatorial jet. Instead, the high-frequency $\overline{u^{\prime} v^{\prime}}$ always diverges at the equator and converges to the north and south of the equator, producing westerly deceleration at the equator flanked by westerly acceleration (less obvious on the northern flank). During the 2015/16 winter, the magnitude of the high-frequency momentum divergence was comparable to that of the low-frequency momentum divergence. Especially during the early winter, most of the zonal wind deceleration at the equator is driven by the high-frequency eddies (Fig. 4a vs Fig. 4c). The zonal 

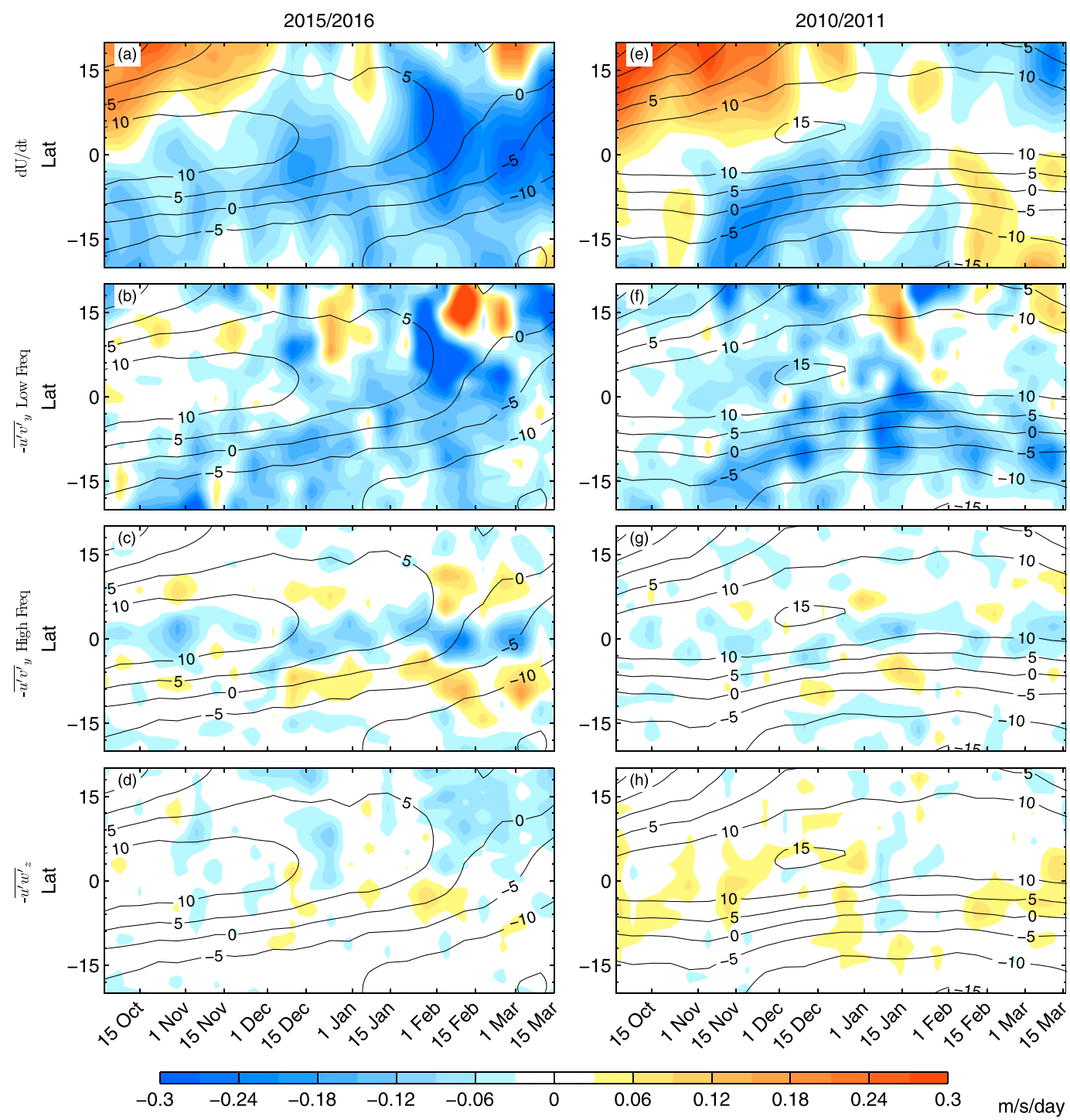

FIG. 4. The weekly evolution of (a),(e) zonal-mean zonal wind acceleration, (b),(f) horizontal eddy momentum flux convergence from low-frequency waves, (c), (g) horizontal eddy momentum flux convergence from high-frequency waves, and (d),(h) vertical eddy momentum flux convergence. Black contours plot the zonalmean zonal wind. Here, (a)-(d) are the 2015/16 winter and (e)-(h) are the 2010/11 winter. All results are plotted at $35.8 \mathrm{hPa}$.

wind tendency from the MRG waves in the 2010/11 winter showed a similar latitudinal distribution to the 2015/16 winter, but with much weaker magnitude. We will discuss how the MRG waves bring about such a zonal wind tendency pattern in section $3 b$.

Kelvin waves result in weak westerly acceleration at the equator throughout the winter, consistent with the weak westerly shear at this level. Stronger Kelvin waves were found during the 2010/11 winter than the 2015/16 winter, especially during the early winter. Note that $\overline{u^{\prime} w^{\prime}}$ is not a perfect representation of Kelvin waves only, as other equatorial waves also consist of $\overline{u^{\prime} w^{\prime}}$. As a result, patches of deceleration are also seen in Figs. $4 d$ and $4 h$.

To further illustrate the evolution of the equatorial westerly jet at $35.8 \mathrm{hPa}$, we identify the jet core as the maximum wind in each latitudinal profile of daily zonal-mean zonal wind within the tropics $\left(20^{\circ} \mathrm{N}-20^{\circ} \mathrm{S}\right)$. Figure 5 plots the evolution of jet-core location and strength during the 2015/16 and 2010/11 winters. In both winters, the jet core drifts northward from the equator to $\sim 7^{\circ} \mathrm{N}$ from October to February, presumably because of the extratropical Rossby wave dissipation at the southern flank of the jet. The jet-core 

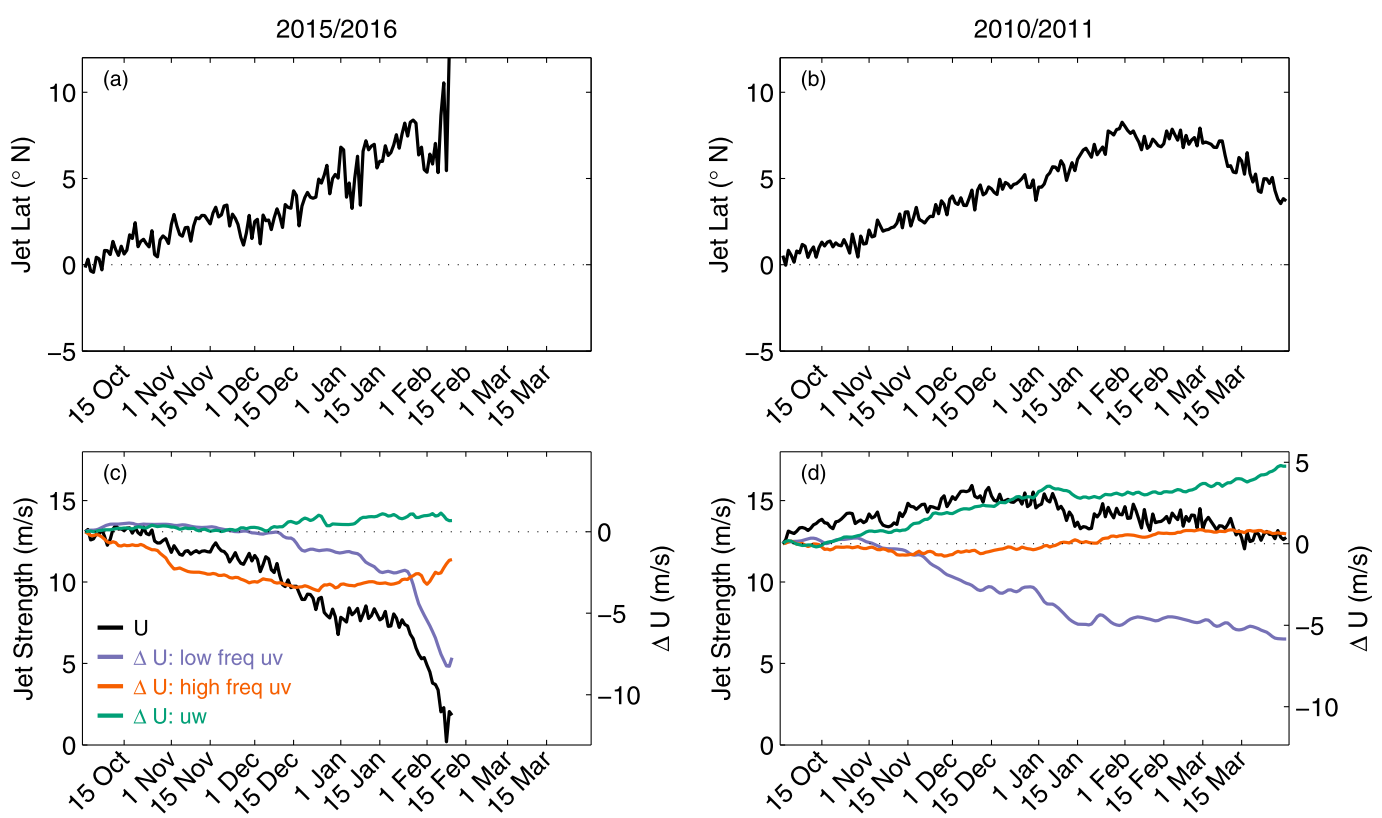

FIG. 5. (a),(b) The daily evolution of the equatorial jet-core position. (c),(d) The daily evolution of the equatorial jet-core strength (black) and the integrated contribution to zonal wind changes at the jet core since 1 Oct from the convergence of the low-frequency horizontal eddy momentum flux (purple), the high-frequency horizontal eddy momentum flux (orange), and the vertical eddy momentum flux (green). Zonal winds and their changes are measured at the latitude of the jet core. Here, (a) and (c) are the 2015/16 winter and (b) and (d) are the 2010/11 winter. All results are plotted at $35.8 \mathrm{hPa}$.

strength, on the other hand, undergoes contrasting evolution in these two winters. In the 2010/11 winter, the jet-core strength stayed relatively constant, consistent with the idealized simulation by O'Sullivan (1997). In the 2015/16 winter, however, the jet-core strength decreased continuously from mid-October. A drastic deceleration started from the end of January, and no westerly jet can be identified after 10 February.

To understand the evolution of the jet-core strength, we calculate the contribution to zonal wind changes at the jet core from the three wave groups by integrating the corresponding eddy momentum flux convergence over time since 1 October. As shown in Fig. $5 \mathrm{c}$, from October to December 2015, the continuous weakening of the jet core was mainly driven by the tropical MRG waves, whereas the contributions from the extratropical Rossby waves and Kelvin waves were mostly small. The drastic deceleration of the jet core around 1 February, on the other hand, was driven by the extratropical Rossby waves. In the 2010/11 winter (Fig. 5d), the extratropical Rossby waves also decelerated the equatorial jet, but there was no equivalent in the 2010/11 winter to the sharp deceleration at the end of January 2016. The MRG waves yielded very little fluctuation in the jet strength during the 2010/11 winter. Kevin waves drove weak acceleration at the jet core in both winters. In the following subsections, we will discuss the exceptionally strong extratropical wave episode occurring around 1 February 2016 and the tropical MRG waves, respectively.

\section{a. The exceptionally strong extratropical Rossby wave episode}

In this subsection, we address the question of why the extratropical Rossby waves dissipated near the jet core during this episode, rather than at the jet flank as theory predicts and most other extratropical waves do. We find that the responsible wave for this episode was a wave packet rather than a circumglobal one, and the spatial confinement may be a key to understanding its behavior

Figure 6a shows a longitude-latitude snapshot of the low-frequency eddy momentum flux $u^{\prime} v^{\prime}$ and the zonal wind. As shown in the figure, the eddy momentum fluxes emanating from the extratropics into the tropics are organized into stripes that tilt with latitude. (The simplest equatorward-propagating Rossby wave, with streamfunction $\psi^{\prime}=A \sin (k x+\ell y)$ and $k \ell<0$, would have $u^{\prime} v^{\prime}=-k \ell A^{2} \cos ^{2}(k x+\ell y)$, with amplitude oscillating between 0 and a positive value, roughly consistent with this figure.) We note that these eddies do not spread out longitudinally over the globe, but instead 

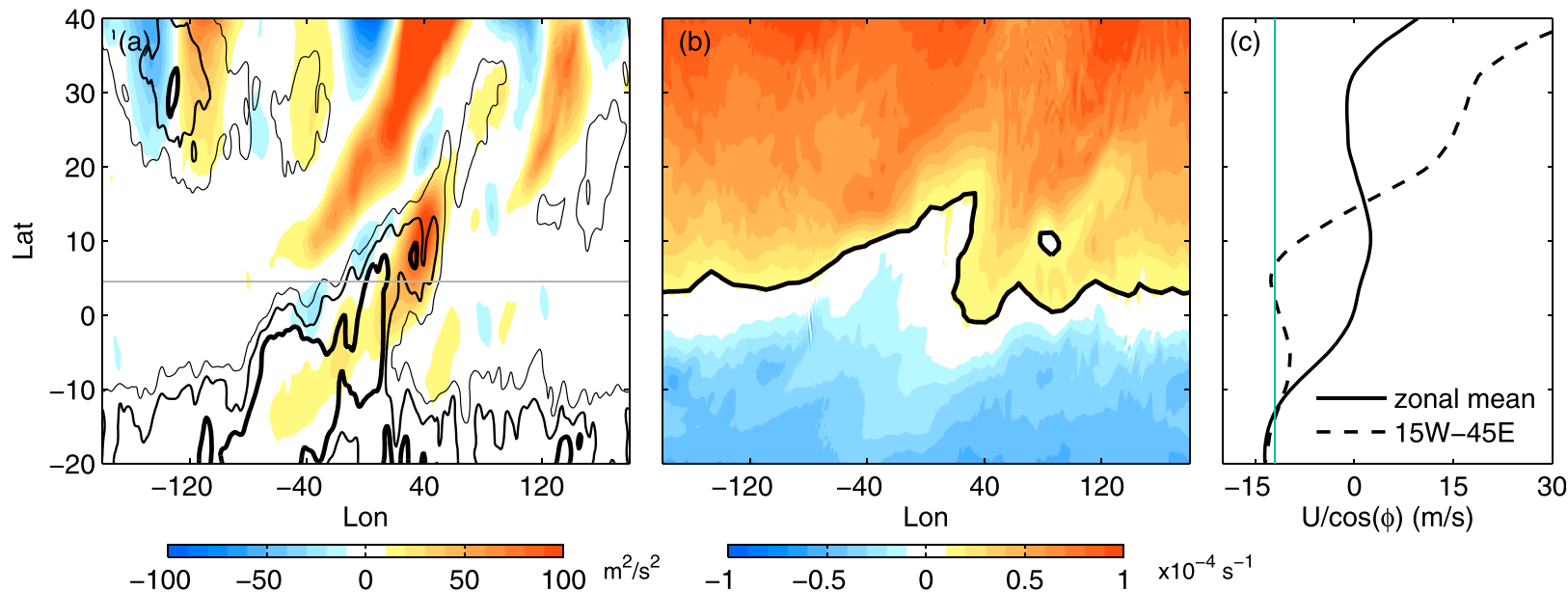

FIG. 6. (a) Snapshot of low-frequency eddy momentum flux $u^{\prime} v^{\prime}$ (color shading) and zonal wind (black contours) at 0600 UTC 7 Feb 2016 (gray line in Fig. 7) at $35.8 \mathrm{hPa}$. For clarity, only easterlies are plotted, with contours of $-5,-10$, and $-15 \mathrm{~m} \mathrm{~s}{ }^{-1}$. Stronger easterlies are plotted with thicker lines. The gray line indicates the latitude where a Hovmöller plot is shown in Fig. 7. (b) Snapshot for PV at the same time. Black lines plot a representative PV contour of $0.11 \times 10^{-4} \mathrm{~s}^{-1}$. (c) Zonal wind profiles averaged over all longitudes (solid line) and over $15^{\circ} \mathrm{W}-45^{\circ} \mathrm{E}$ (dashed line). The vertical green line marked the phase speed of $-12 \mathrm{~m} \mathrm{~s}$ at which the wave packet is traveling.

form a wave packet with width of $\sim 100^{\circ}$. Collocated with the wave packet is a tongue of strong easterlies that extends from the Southern Hemisphere to the Northern Hemisphere. The zonal wind experienced by the wave packet is then quite different from the zonal mean wind profile as shown in Fig. 6c. While the zonal mean winds show westerlies between $20^{\circ} \mathrm{N}$ and $5^{\circ} \mathrm{S}$, the zonal wind averaged over $15^{\circ} \mathrm{W}-45^{\circ} \mathrm{E}$ shows easterlies occupying the region south of $\sim 15^{\circ} \mathrm{N}$. As shown in Fig. 7, this wave packet moves westward with a phase speed of $\sim-12 \mathrm{~m} \mathrm{~s}^{-1}$. If judging by the zonal mean wind profile, the critical latitude where zonal wind matches the phase speed would be around $10^{\circ} \mathrm{S}$. However, judging by the local zonal wind, the critical latitude would be around $5^{\circ} \mathrm{N}$. Indeed, we see the magnitude of $u^{\prime} v^{\prime}$ quickly drops as it crosses $5^{\circ} \mathrm{N}$ (Fig. 6a), and a potential vorticity (PV) overturning and reversal of its meridional gradient are seen in the region between $0^{\circ}$ and $10^{\circ} \mathrm{N}$, centered around $30^{\circ} \mathrm{E}$ (Fig. 6b), both of which indicate the dissipation or absorption of the wave packet near the local critical latitude.

The coexistence of the wave packet and the strong easterlies is not just coincidence. These local easterlies arise from the passing of the wave itself, indicating that they are a signature of wave breaking. As evident from Fig. 7, the easterlies propagate westward with the wave packet (indicated by the strong poleward eddy momentum flux). Hence the dissipation of this wave packet always occurs at the local critical latitude that is located much northward of the zonal-mean critical latitude. This is consistent with the westward-propagating Ertel PV knot observed in the equatorial region shown by Coy et al. (2017, their Fig. 13). Similar episodes of a strong enough wave packet leading to some dissipation away from the zonal-mean critical latitude have been observed from time to time, such as the deceleration centered around $10^{\circ} \mathrm{N}$ between 1 and 15 December

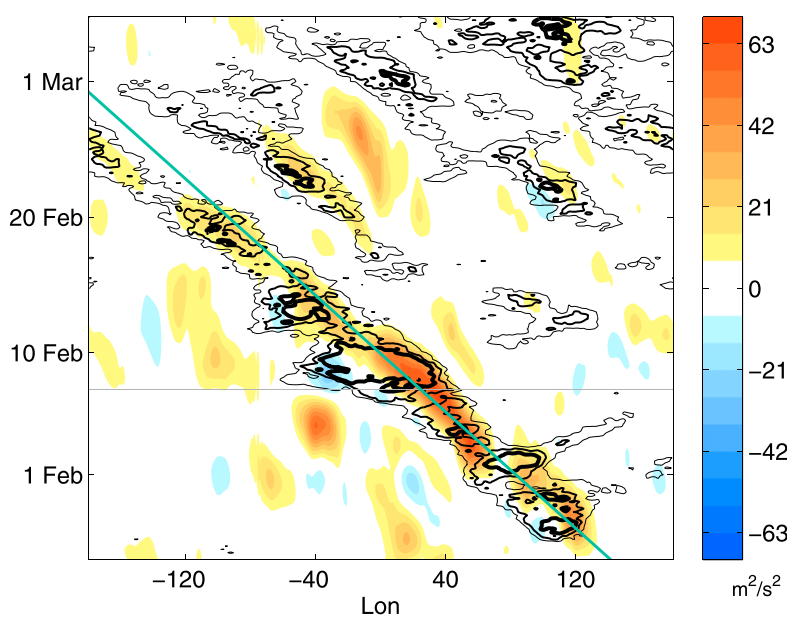

FIG. 7. Hovmöller plot for low-frequency eddy momentum flux $u^{\prime} v^{\prime}$ (color shading) and zonal wind (black contours) at $4.5^{\circ} \mathrm{N}$ (gray line in Fig. 6a) at $35.8 \mathrm{hPa}$. For clarity, only easterlies are plotted, with contours of $-5,-10$, and $-15 \mathrm{~m} \mathrm{~s}^{-1}$. Stronger easterlies are plotted with thicker lines. The gray line indicates the time when the snapshots in Fig. 6 are taken. The green line represent an easterly phase speed of $12 \mathrm{~m} \mathrm{~s}^{-1}$. 
2015 (Fig. 4b) and the deceleration centered around $3^{\circ} \mathrm{N}$ in late November 2010 (Fig. 4f). But typically those wave packets transport less momentum and are less persistent, and hence exert much weaker impact on the background zonal wind. As a single wave packet, its dissipation or absorption must be confined locally initially. This also explains why the strong deceleration in the equatorial westerly was vertically confined within a thin layer in February 2016.

This behavior of a wave breaking before reaching its critical latitude has been discussed by Fyfe and Held (1990) and others, the breaking occurring where the phase speed of the wave with respect to the mean flow drops below the eddy zonal wind perturbation amplitude $u^{\prime}$. Fyfe and Held (1990) described how a bifurcation to strong wave breaking and mean-flow deceleration can occur with increasing wave amplitude because of feedback with the zonal flow, but in the context of an incident wave of a single zonal wavenumber rather than a wave packet. The interaction between a wave packet and the mean flow has been modeled (e.g., Magnusdottir and Haynes 1999; Esler et al. 2000), but has typically focused on the potential for reflection rather than an abrupt transition from transmission through equatorial westerlies to wave breaking. Waugh et al. (1994) reported that the breaking of a stationary wave train may occur in the absence of the critical line given that the wave forcing is strong enough to create stagnation points, which is equivalent to having a local critical line. Enomoto and Matsuda (1999) simulated the wave packet propagation with a zonally varying mean flow, and showed that the behavior of the wave packet depends strongly on the relative location between the wave packet and local easterlies. Campbell (2004) simulated a wave packet with stationary forcing in an initially zonally symmetric basic flow and showed that the absorption of the wave packet near the critical line led to strong local perturbation in the basic flow. All these model studies support our argument that a wave packet interacts with the local background flow rather than the zonal mean.

However, unlike in idealized simulations, it is much more ambitious to define the wave and the mean flow in observations as there may not be a clear scale separation between them. Here, we made this somewhat arbitrary choice of averaging over $15^{\circ} \mathrm{W}-45^{\circ} \mathrm{E}$ to represent the mean flow. While this may not be the optimal definition, the mean flow under this definition gives a much better estimation of the latitude where wave dissipation/absorption occurs than the zonal mean winds. This strongly suggests that it is to the local winds rather than the zonal mean winds that a wave packet responds. The fact that it is a wave packet rather than a circumglobal wave also leads to ambiguity in determining the wavenumber from the spectra analysis. This is why this single wave packet projects to a seemingly broad patch of signal ranging over wavenumbers $1-3$ in Fig. 2.

\section{b. The tropical MRG waves}

The equatorial MRG waves are a major driver of the QBO. The analytical solution for the MRG wave (Matsuno 1966) indicates EP fluxes pointing upward centered off the equator. During the 2015/16 winter, the vertical EP flux over the easterly highfrequency band was generally consistent with this prediction. The horizontal EP flux, on the other hand, surprisingly showed strong convergence and divergence in the tropics throughout the stratosphere. These horizontal EP flux anomalies are brought about by the horizontal eddy momentum flux $\overline{u^{\prime} v^{\prime}}$. This contradicts with Matsuno's solution, which yields zero $\overline{u^{\prime} v^{\prime}}$. Then how did the nonzero $\overline{u^{\prime} v^{\prime}}$ arise from the MRG waves?

To address this question, we analyze the structure of these waves. We use the meridional wind at the equator $v_{0}$ as the reference and calculate the coherence and the phase difference of different variables with regards to this reference. The coherence and phase are calculated using the averaged spectra over the easterly waves with frequency between 0.15 and 0.5 cpd following Hayashi [1971, their Eqs. (4.12) and (4.13)]. Figure 8 shows the coherence square and the phase difference in zonal and meridional winds as well as in temperature with $v_{0}$. Consistent with the analytical solution for the MRG wave (Matsuno 1966), the meridional wind anomalies align along the longitude lines showing near-zero phase difference with $v_{0}$ at all latitudes. The strongest meridional wind anomalies are located at the equator, and the magnitudes decay away from the equator. The temperature and zonal wind anomalies associated with $v_{0}$ are the strongest off the equator at $\sim 7^{\circ} \mathrm{N} / \mathrm{S}$. The temperature anomalies are antisymmetric about the equator, aligning roughly in phase with the meridional wind anomalies in the Northern Hemisphere and out of phase in the Southern Hemisphere. The zonal wind anomalies are in quadrature with the meridional wind anomalies, which lie to the east of $v_{0}$ in the Northern Hemisphere and to the west in the Southern Hemisphere.

Upon close examination, we see that the phase difference between zonal and meridional wind is not exactly $\pm \pi / 2$ as the analytical solution predicts (Matsuno 1966), especially between $10^{\circ} \mathrm{N}$ and $10^{\circ} \mathrm{S}$. 

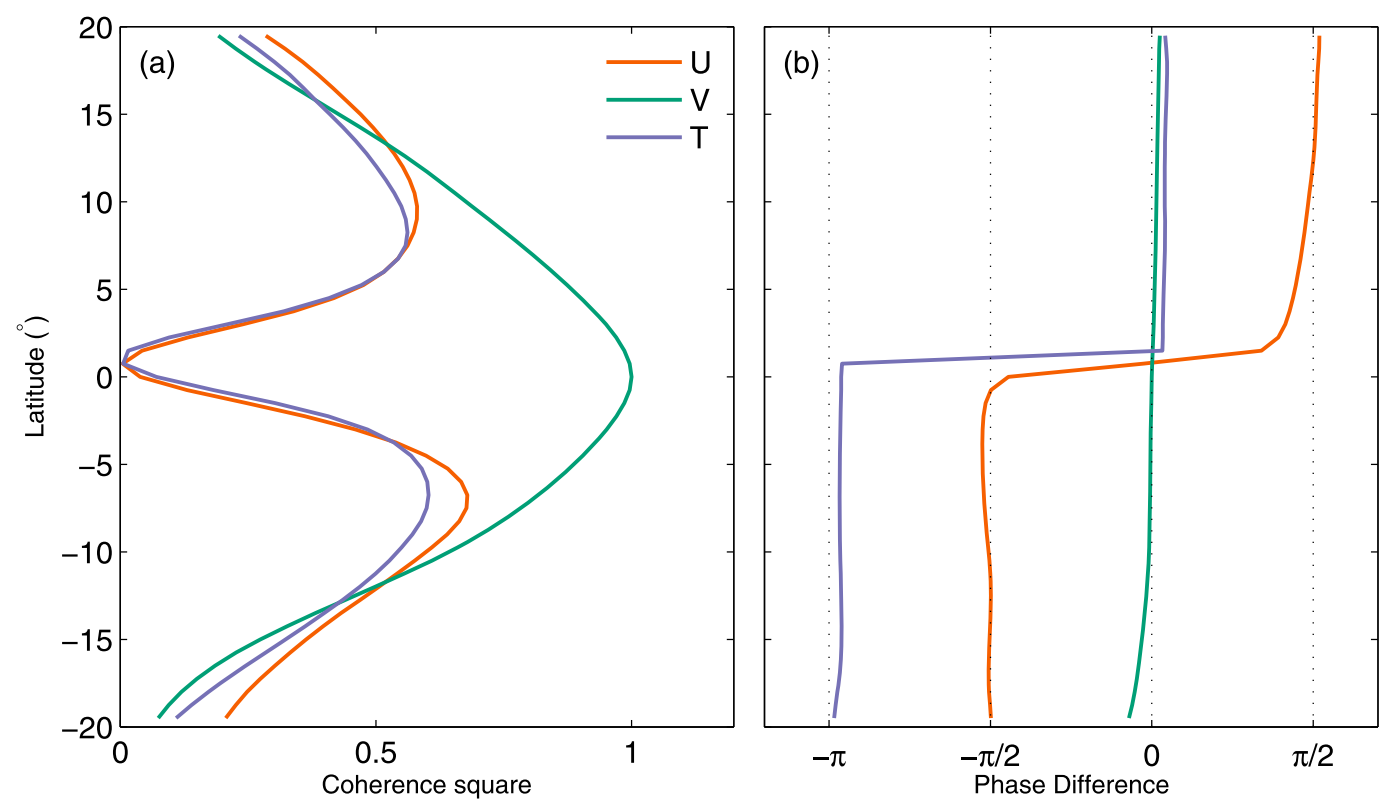

FIG. 8. (a) Coherence square and (b) phase difference of zonal and meridional wind and temperature with respect to the meridional wind at the equator for easterly waves with frequency between 0.15 and 0.5 cpd for November 2015-February 2016 at $35.8 \mathrm{hPa}$.

This seemingly small departure from quadrature would result in nonzero $\overline{u^{\prime} v^{\prime}}$. To estimate how much $\overline{u^{\prime} v^{\prime}}$ results from this phase difference, we write the zonal and meridional wind anomalies as

$u^{\prime}=A_{u} \cos \left(k x+\omega t+\varphi_{u}\right)=A_{u} \cos \left(k x+\omega t+\varphi_{0}+\Delta \varphi_{u}\right)$, $v^{\prime}=A_{v} \cos \left(k x+\omega t+\varphi_{v}\right)=A_{v} \cos \left(k x+\omega t+\varphi_{0}+\Delta \varphi_{v}\right)$,

in which $A$ is the amplitude of the wave, $k$ is zonal wavenumber, $\omega$ is frequency, $\varphi$ is phase, $\varphi_{0}$ is phase for $v_{0}$, and $\Delta \varphi$ is the phase difference with respect to $v_{0}$. Further noted that the coherence square with $v_{0}$ measures the fraction of variation that is associated with this MRG wave, we have

$$
\frac{A_{u}^{2}}{2}=P_{u} \operatorname{coh}_{u}^{2}, \quad \frac{A_{v}^{2}}{2}=P_{v} \operatorname{coh}_{v}^{2},
$$

in which $P$ is the power spectrum of the corresponding variables, and coh is the coherence with respect to $v_{0}$. From Eqs. (1) and (2), we can derive the corresponding eddy momentum flux:

$$
\begin{aligned}
{\left[\overline{u^{\prime} v^{\prime}}\right] } & =\frac{1}{2} A_{u} A_{v} \cos \left(\Delta \varphi_{u}-\Delta \varphi_{v}\right) \\
& =\sqrt{P_{u} P_{v}} \operatorname{coh}_{u} \operatorname{coh}_{v} \cos \left(\Delta \varphi_{u}-\Delta \varphi_{v}\right),
\end{aligned}
$$

in which the square brackets represent temporal average.
Figure 9 compares $\left[\overline{u^{\prime} v^{\prime}}\right]$ as well as its convergence calculated from Eq. (3) with those from direct calculation of high-frequency winds averaged over the 2015/16 winter. General agreement is seen in both the magnitude as well as the latitudinal structure. The northward momentum flux in the Northern Hemisphere comes from $\Delta \varphi_{u}<\pi / 2$ there, and the southward momentum flux in the Southern Hemisphere is due to the fact that $\Delta \varphi_{u}<-\pi / 2$ there. As a result, eddy momentum diverges at the equator and converges off the equator. While the difference between $\Delta \varphi_{u}$ and its theoretical value $\pm \pi / 2$ seems to be trivial, it is large enough to drive an eddy momentum flux divergence on the order of $0.1 \mathrm{~m} \mathrm{~s}^{-1} \mathrm{day}^{-1}$ at the equator. This agreement between Eq. (3) and the directly calculated high-frequency eddy momentum fluxes confirms the deformed MRG wave as the main driver for the high-frequency eddies in the 2015/16 winter.

It is not clear why the observed MRG waves have such deformation from Matsuno's classic wave structure (Matsuno 1966). One possible cause might be the background flow, which was assumed to be zero in Matsuno's solution (Matsuno 1966). Andrews and McIntyre (1976) showed that both equatorial Kelvin and MRG waves possess nonzero $\overline{u^{\prime} v^{\prime}}$ with weak shear in the background flow. We examine the highfrequency eddy momentum flux throughout the reanalysis period, and find that the tripole structure 

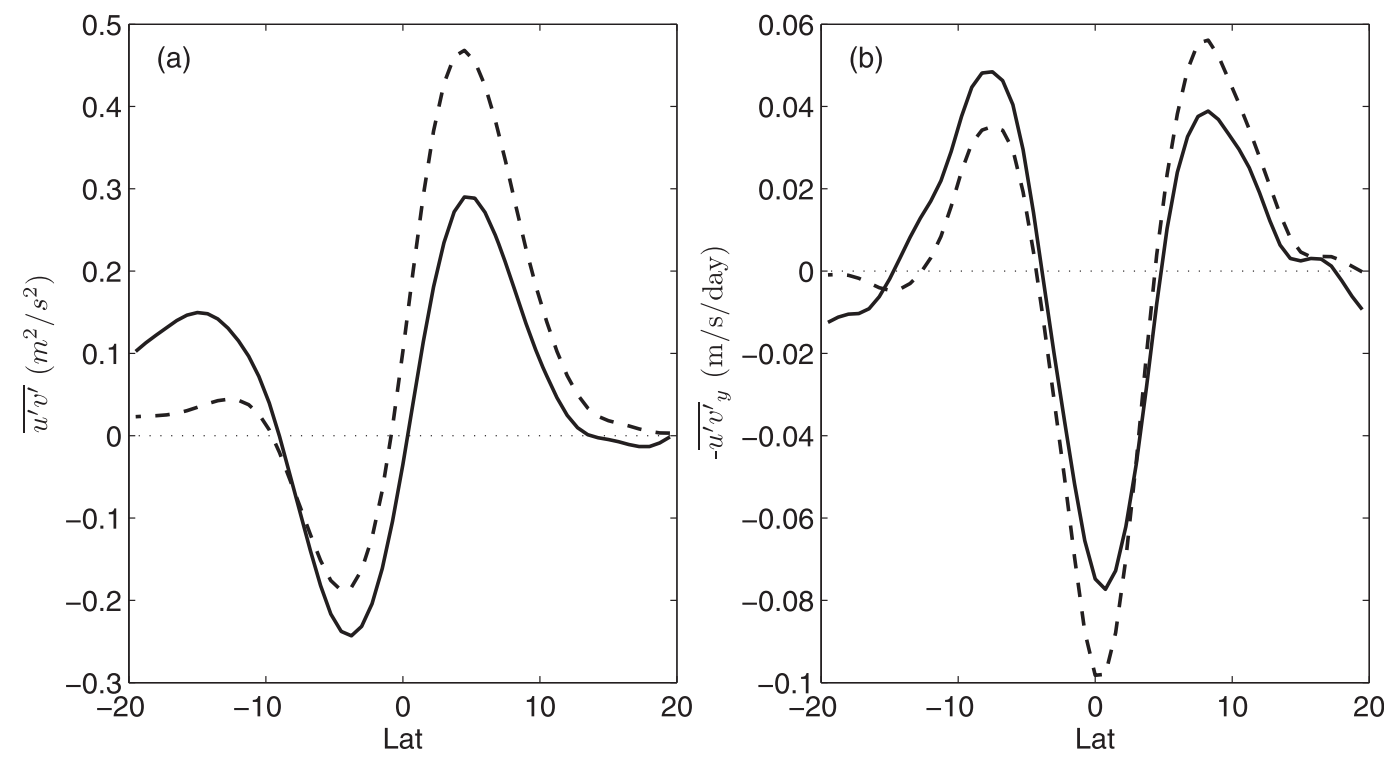

FIG. 9. (a) Horizontal eddy momentum flux $\overline{u^{\prime} v^{\prime}}$ from high-frequency waves averaged over November 2015February 2016 (solid line) and estimated from Eq. (3) (dashed line) at $35.8 \mathrm{hPa}$. (b) As in (a), but for horizontal eddy momentum flux convergence. See text for more explanation.

in the eddy momentum convergence associated with the deformed MRG waves shown in Fig. 9b is not unique in the 2015/16 winter. Rather, similar latitudinal structure is commonly observed. In fact, this tripole structure dominates the variations in the tropical monthly high-frequency eddy momentum flux convergence since 1979 as shown in Fig. 10.

We further find the sign of the tripole structure from the MRG wave deformation depends on the sign of the vertical shear in the background flow. We regress the space-time spectra of the eddy momentum flux convergence upon this tripole structure, and composite the regression coefficients according to the QBO phase. The phase of the QBO cycle is determined from the two leading EOFs of the stratospheric equatorial zonal-mean zonal winds (Wallace et al. 1993; more details are given in the appendix). Figure 11 shows the composited spectra as well as the equatorial zonal wind profile over four QBO phase bands. Note that the QBO phase during 2015/16 winter is within the first QBO phase band plotted in Figs. 11a and 11e. In all four cases, the regression coefficients are strong along the MRG dispersion lines, indicating that the MRG waves contribute to the tripole structure in momentum convergence. When background flow shows westerly shear (Figs. 11a,d), the composited spectra is negative along the MRG dispersion lines (Figs. 11e,h), that is, divergence of eddy momentum and westerly deceleration at the equator and momentum convergence and westerly acceleration off the equator. When background flow shows easterly shear (Figs. 11b,c), the composite spectra also flip signs (Figs. 11f,g). When there are easterlies below the level considered (Figs. 11c,d), some of the MRG waves will be absorbed at the lower levels, and only MRG waves with faster easterly phase speed can penetrate deep into the stratosphere. Such filtering effect is apparent in the spectra (Fig. 11e vs Fig. 11h and Fig. 11f vs Fig. 11g). Using data at a different level yields similar results (not shown).

We sum the regression coefficients of the eddy momentum divergence over the frequency-wavenumber range for the MRG waves (i.e., all easterly wavenumbers and $0.15 \leq \omega \leq 0.5 \mathrm{cpd})$, which represents the strength of the tripole structure in the eddy momentum flux divergence due to the MRG waves. Here positive values indicate momentum divergence at the equator. Figure 12a compares this strength during the 2015/16 winter to that in earlier QBO cycles with similar QBO phases. We see that the 2015/16 winter shows much stronger tripole structure than before, even excluding February 2016 when the QBO disruption has fully developed, leading to more momentum divergence at the equator and more convergence off the equator. Furthermore, we calculate the phase difference $\Delta \varphi_{u}$ and $\Delta \varphi_{v}$ in these earlier QBO cycles as in the $2015 / 16$ winters. Figure $12 \mathrm{~b}$ compares the difference in $\cos \left(\Delta \varphi_{u}-\Delta \varphi_{v}\right)$ between $5^{\circ}-10^{\circ} \mathrm{N}$ and $5^{\circ}-10^{\circ} \mathrm{S}$ of the selected QBO cycles. The latitudinal range is chosen to represent the region where the MRG 


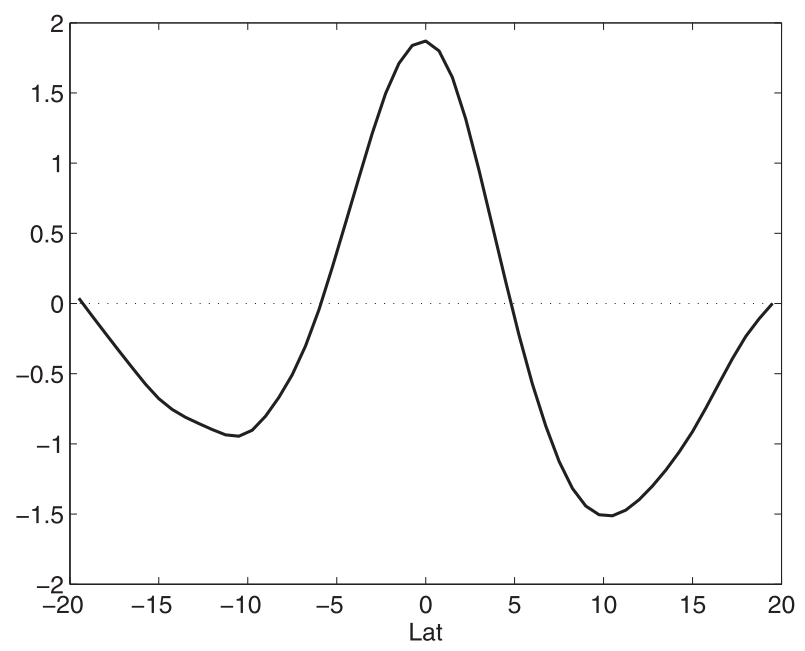

FIG. 10. The leading EOF pattern (unitless) in monthly highfrequency horizontal eddy momentum flux convergence at $35.8 \mathrm{hPa}$ over $20^{\circ} \mathrm{N}-20^{\circ} \mathrm{S}$ for $1979-2016$.

wave-related eddy momentum flux is the strongest. This quantity represents the deformation of the MRG waves, and is proportional to the poleward eddy momentum flux as in Eq. (3). With westerly shear, we see that the MRG wave deforms in such a way that poleward eddy momentum flux is produced in most cases. Comparing Figs. 12a and 12b, the variations in the tripole structure strength is found to be correlated with the deformation factor, both showing stronger values in the recent years and weaker values in late 1990s and early 2000s. The much stronger MRG wave-related $\overline{u^{\prime} v^{\prime}}$ in 2015/16 winter seems to be a combination of stronger wave deformation as well as stronger wave amplitude. While there is concern regarding the consistency of the reanalysis data over time, abnormal equatorial waves during the 2015/16 winter are plausible given the record-breaking El Niño observed at the same time (e.g., Avery et al. 2017; Hu and Fedorov 2017; Santoso et al. 2017).

\section{Conclusions and discussion}

We study the early development of the 2015/16 QBO disruption. We find that the westerly deceleration in the midst of the equatorial westerly jet was driven not only by the extratropical Rossby waves that propagate horizontally into the tropics, but also by the tropical MRG waves. These tropical waves were masked by the extratropical waves in the previous analyses based on the total eddy fluxes (Osprey et al. 2016; Coy et al. 2017; Barton and McCormack 2017; Watanabe et al. 2018). But as shown in our study, the tropical waves have made appreciable contributions to the development of the QBO disruption.

Consistent with the critical-latitude argument, the extratropically generated waves are found to pass through the equatorial region and dissipate at the southern flank of the equatorial jet, and therefore only decelerate the flank but not the core of the jet in most cases. However, as a wave packet shifts winds from their zonal mean, if the wave packet is of large-enough amplitude, the local wind profile experienced by the wave packet can be very different from the zonal mean profile. The resulting local critical latitude can therefore be far away from the zonal mean. This is why dissipation of easterly waves is possible at a particular latitude where zonal mean wind is westerly. An episode of exceptionally strong longitudinally confined extratropical wave packet was observed in early February 2016, of which the local critical latitude resided roughly $15^{\circ}$ north of the zonal mean one. This particular wave packet led to localized and drastic deceleration at the center of the zonal mean jet and ultimately destroyed the equatorial westerly jet.

On the other hand, the tropical MRG waves decelerated the equatorial jet core throughout the 2015/16 winter. The horizontal eddy momentum fluxes associated with the MRG waves diverged at the equator, and converged off the equator. Such eddy momentum anomalies arise from a deformation of the wave structure. It is not clear why the deformation occurs. But based on the reanalysis data, we show that such horizontal eddy momentum anomalies associated with the MRG waves are commonly observed throughout the stratosphere, and the sign of these anomalies largely depends on the vertical shear of the background flow. Comparing to other months that have similar equatorial zonal wind structure, the 2015/16 winter shows a much stronger horizontal eddy momentum flux associated with the MRG waves.

While the exceptionally strong extratropical wave episode is the one that destroyed the equatorial westerly jet and triggered the regime shift, we suggest that the continuous deceleration from the tropical waves beforehand is important for preconditioning the flow. Without these tropical waves, the extratropical waves would interact with a stronger jet. Even with the same wave amplitude, the wave-passage-induced local critical lines would be farther south, and their dissipation may not affect the jet-core strength as much. In addition, the deceleration from the tropical waves during the early winter may contribute to a condition that favors the penetration of extratropical waves into the tropics, which is highlighted as the key for successful hindcast simulations by Watanabe et al. (2018). 

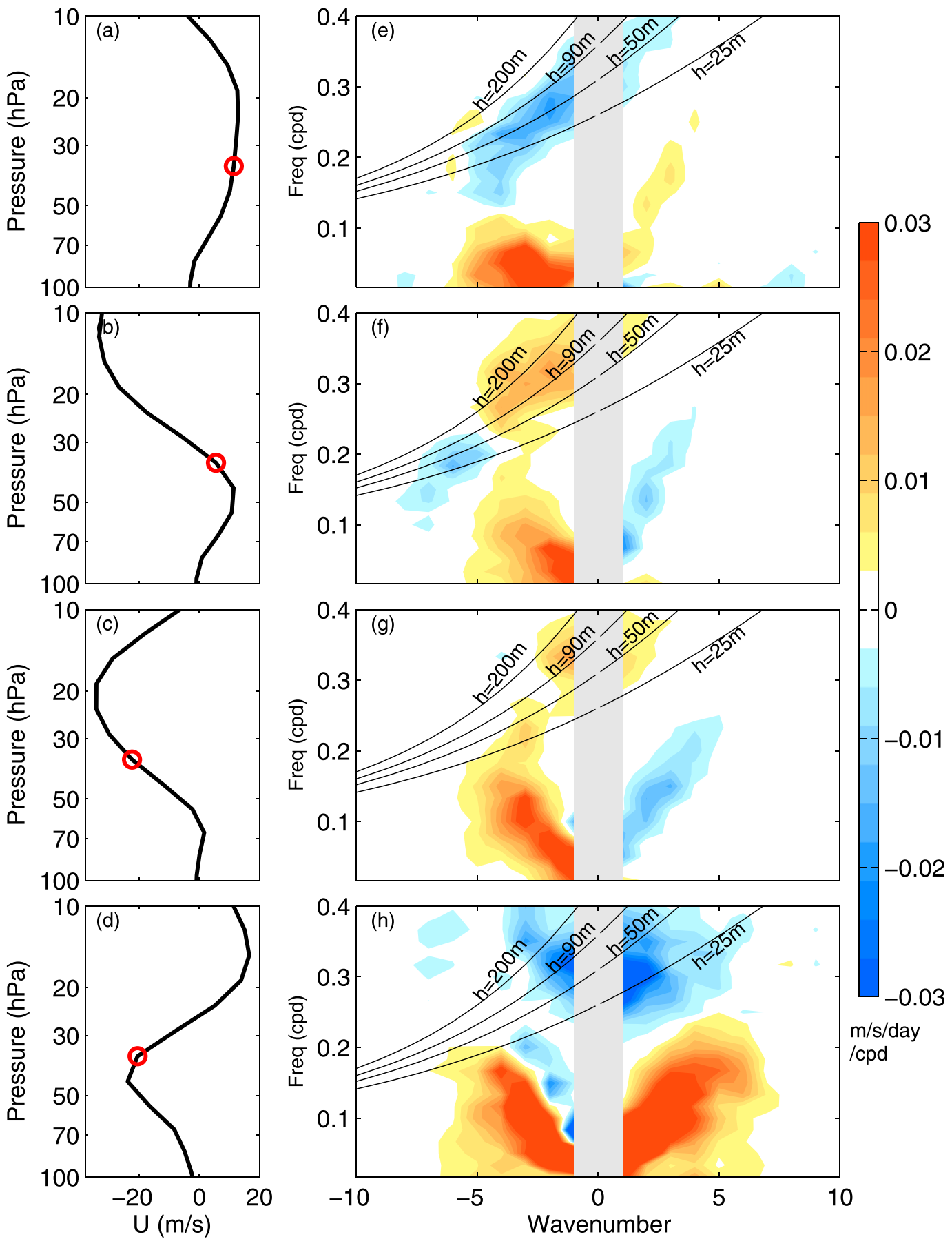

FIG. 11. (a)-(d) Equatorial zonal wind profiles and (e)-(h) regression coefficients of the space-time spectra of horizontal eddy momentum flux convergence upon the latitudinal pattern shown in Fig. 10 averaged for QBO phase in the range of (a),(e) $[-0.84 \pi,-0.64 \pi]$, (b),(f) $[-0.34 \pi,-0.24 \pi]$, (c), (g) $[0.16 \pi, 0.36 \pi]$, and (d),(h) $[0.66 \pi, 0.86 \pi]$. The red circles on the wind profiles indicate the level where the spectra are calculated. The spectra are superimposed by the dispersion curves of the mixed Rossby-gravity wave and $n=0$ eastward inertial gravity wave with equivalent depth $h=25,50,90$, and $200 \mathrm{~m}$.

We compare the abnormal 2015/16 winter with the 2010/11 winter, when the tropical horizontal eddy momentum flux was also large but no QBO disruption was observed. The key differences that set apart the two winters are the existence of exceptionally strong and persistent extratropical wave 

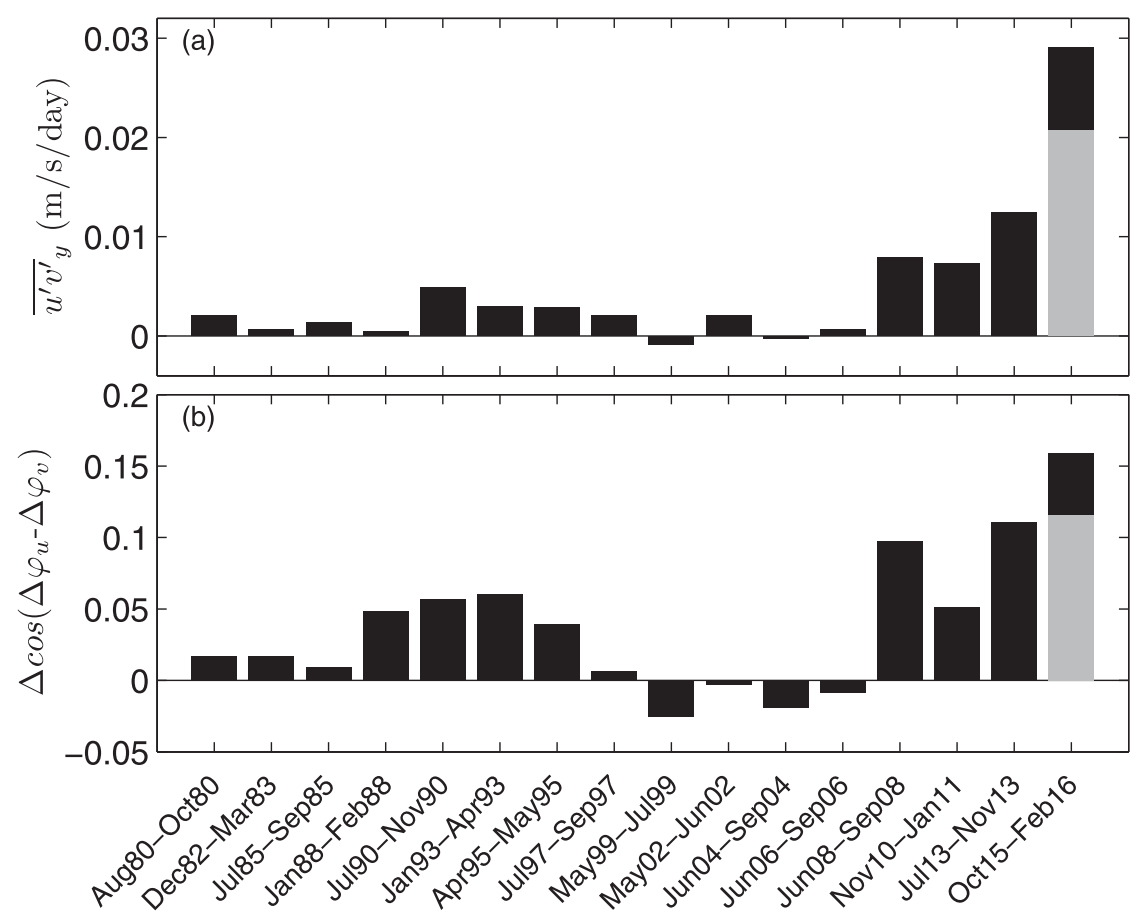

FIG. 12. (a) The strength of the eddy momentum divergence tripole contributed by easterly waves with frequency between 0.15 and $0.5 \mathrm{cpd}$ averaged over months when QBO phase is in the range of $[-0.84 \pi,-0.64 \pi]$ in each cycle at $35.8 \mathrm{hPa}$. The gray bar indicates the average from October 2015 to January 2016. (b) As in (a), but for the deformation factor $\left.\cos \left(\Delta \varphi_{u}-\Delta \varphi_{v}\right)\right|_{5^{\circ} \mathrm{N}-10^{\circ} \mathrm{N}}-\left.\cos \left(\Delta \varphi_{u}-\Delta \varphi_{v}\right)\right|_{5^{\circ} \mathrm{S}-10^{\circ} \mathrm{s}}$. See text for more explanation.

packets and the strength of the horizontal eddy momentum flux associated with MRG waves. This work suggests that further studies of the transition from the propagating of extratropical Rossby wave packets through the tropics to strong breaking events near the equator are called for. In addition, we feel that the horizontal momentum fluxes in the MRG waves and their potential for modifying the extratropical wave breaking needs to be better understood. Finally, whether these anomalies in eddy momentum flux due to extratropical wave breaking and in MRG waves amplitudes observed in the 2015/16 winter are part of the natural variability or effects from climate change requires further investigation.

Acknowledgments. This report was prepared by $\mathrm{Pu}$ Lin under Award NA14OAR4320106 from the National Oceanic and Atmospheric Administration, U.S. Department of Commerce. The statements, findings, conclusions, and recommendations are those of the author(s) and do not necessarily reflect the views of the National Oceanic and Atmospheric Administration, or the U.S. Department of Commerce.

\section{APPENDIX}

\section{Constructing the QBO Phase}

Following Wallace et al. (1993), we first calculate the EOFs from the monthly zonal mean zonal wind at the equator for 1979-2016 between 112.3 and $9.9 \mathrm{hPa}$. Equal weight is given to wind anomalies at each level when calculating the EOFs. Figure A1a shows the two leading EOFs, and the corresponding principal components (PCs) are shown in Fig. A1b. The alternative descending wind anomalies of the QBO are reflected as the counterclockwise orbits in the PC space. One can then define the amplitude and phase of the QBO from these orbits. In particular, the phase is calculated as the angle for the complex number $\mathrm{PC} 1+i \mathrm{PC} 2$. The resulting time series of the QBO phase is plotted in Fig. A1c. The 2015/16 QBO disruption clearly manifests itself in a deviation from the usual orbits (red crosses in Fig. A1b). Similar QBO phase evolution is shown by Tweedy et al. (2017). In this study, the QBO phase is used as a metric to sort out equatorial zonal wind profiles that have similar vertical structures. To this purpose, 

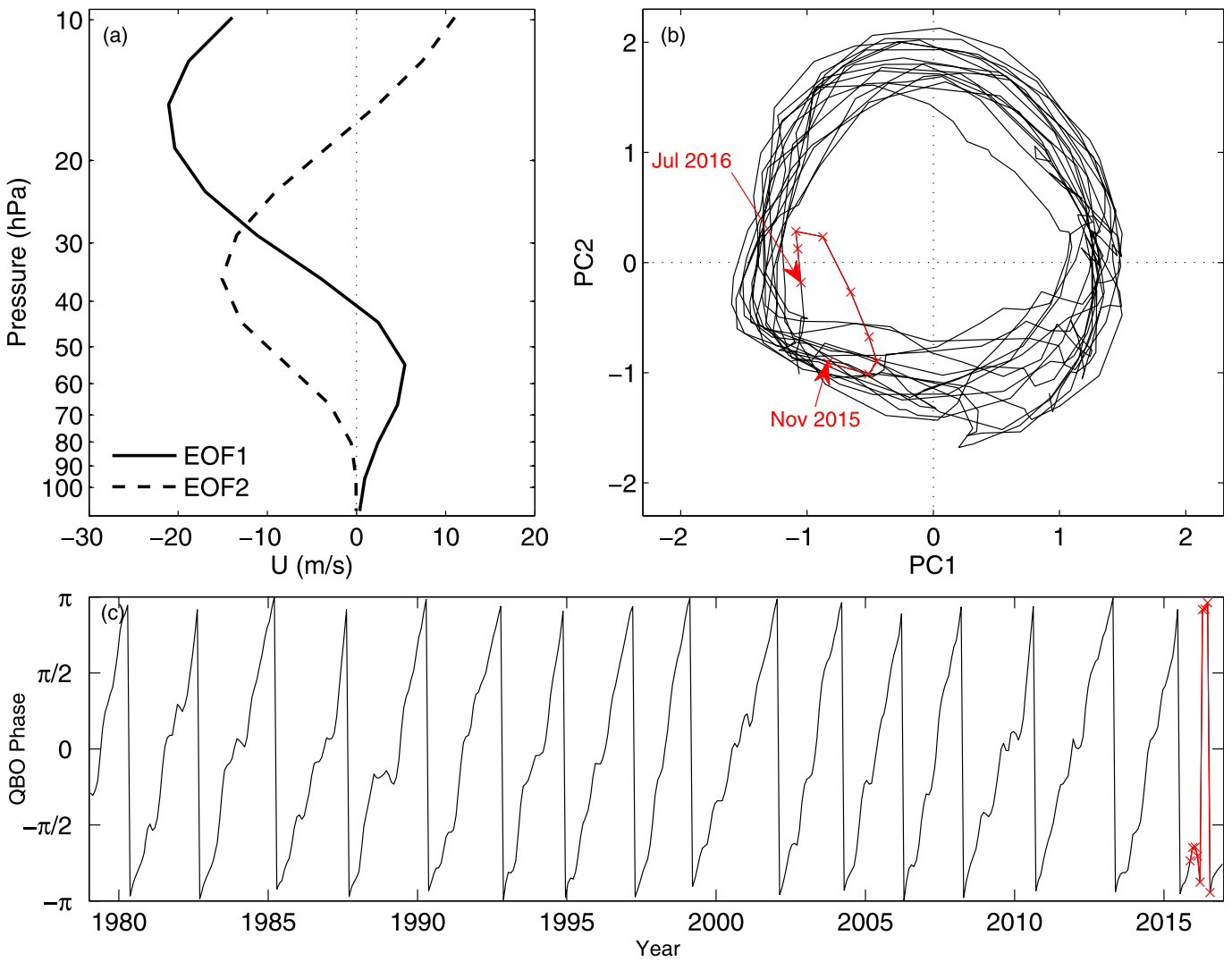

FIG. A1. (a) The first two EOFs of monthly equatorial zonal-mean zonal winds for 1979-2016. (b) The corresponding PCs. (c) Time series of QBO phase defined from the two PCs. The months between November 2015 and July 2016 when QBO disruption occurred are marked by red crosses.

defining the QBO phase in other ways or sorting out wind profiles by root-mean-square difference as done by Osprey et al. (2016) would lead to similar results to what is shown here.

\section{REFERENCES}

Abalos, M., W. J. Randel, and T. Birner, 2016: Phase-speed spectra of eddy tracer fluxes linked to isentropic stirring and mixing in the upper troposphere and lower stratosphere. J. Atmos. Sci., 73, 4711-4730, https://doi.org/10.1175/ JAS-D-16-0167.1.

Andrews, D. G., and M. E. McIntyre, 1976: Planetary waves in horizontal and vertical shear: Asymptotic theory for equatorial waves in weak shear. J. Atmos. Sci., 33, 2049-2053, https:// doi.org/10.1175/1520-0469(1976)033<2049:PWIHAV>2.0.CO;2.

—_ J. R. Holton, and C. B. Leovy, 1987: Middle Atmosphere Dynamics. International Geophysics Series, Vol. 40, Academic Press, 489 pp.

Avery, M. A., S. M. Davis, K. H. Rosenlof, H. Ye, and A. E. Dessler, 2017: Large anomalies in lower stratospheric water vapour and ice during the 2015-2016 El Niño. Nat. Geosci., 10, 405-409, https://doi.org/10.1038/ngeo2961.

Baldwin, M. P., and Coauthors, 2001: The quasi-biennial oscillation. Rev. Geophys., 39, 179-229, https://doi.org/10.1029/ 1999RG000073.
Barton, C. A., and J. P. McCormack, 2017: Origin of the 2016 QBO disruption and its relationship to extreme El Niño events. Geophys. Res. Lett., 44, 11 150-11157, https://doi.org/10.1002/ 2017GL075576.

Campbell, L. J., 2004: Wave-mean-flow interactions in a forced Rossby wave packet critical layer. Stud. Appl. Math., 112, 39-85, https://doi.org/10.1111/j.1467-9590.2004.01587.x.

Coy, L., P. A. Newman, S. Pawson, and L. R. Lait, 2017: Dynamics of the disrupted 2015/16 quasi-biennial oscillation. J. Climate, 30, 5661-5674, https://doi.org/10.1175/JCLI-D-16-0663.1.

Dee, D. P., and Coauthors, 2011: The ERA-Interim reanalysis: Configuration and performance of the data assimilation system. Quart. J. Roy. Meteor. Soc., 137, 553-597, https://doi.org/ 10.1002/qj.828.

Dunkerton, T. J., 1997: The role of gravity waves in the quasibiennial oscillation. J. Geophys. Res., 102, 26053-26076, https://doi.org/10.1029/96JD02999.

Enomoto, T., and Y. Matsuda, 1999: Rossby wavepacket propagation in a zonally-varying basic flow. Tellus, 51, 588-602, https://doi.org/10.3402/tellusa.v51i5.14477.

Esler, J. G., L. M. Polvani, and R. A. Plumb, 2000: The effect of a Hadley circulation on the propagation and reflection of planetary waves in a simple one-layer model. J. Atmos. Sci., 57, 1536-1556, https://doi.org/10.1175/1520-0469(2000) 057<1536:TEOAHC $>2.0$. CO;2.

Fyfe, J., and I. Held, 1990: The two-fifths and one-fifth rules for Rossby wave breaking in the WKB limit. J. Atmos. Sci., 47, 
697-706, https://doi.org/10.1175/1520-0469(1990)047<0697: TTFAOF $>2.0 . \mathrm{CO} ; 2$.

Hayashi, Y., 1971: A generalized method of resolving disturbances into progressive and retrogressive waves by space Fourier and time cross-spectral analyses. J. Meteor. Soc. Japan, 49, 125-128, https://doi.org/10.2151/jmsj1965.49.2_125.

Hitchcock, P., P. H. Haynes, W. J. Randel, and T. Birner, 2018: The emergence of shallow easterly jets within QBO westerlies. J. Atmos. Sci., 75, 21-40, https://doi.org/10.1175/ JAS-D-17-0108.1.

Holt, L. A., M. J. Alexander, L. Coy, A. Molod, W. Putman, and S. Pawson, 2016: Tropical waves and the quasi-biennial oscillation in a 7-km global climate simulation. J. Atmos. Sci., 73, 3771-3783, https://doi.org/10.1175/JAS-D-15-0350.1.

Holton, J. R., and R. S. Lindzen, 1972: An updated theory for the quasi-biennial cycle of the tropical stratosphere. J. Atmos. Sci., 29, 1076-1080, https://doi.org/10.1175/1520-0469(1972)029<1076: AUTFTQ $>2.0 . \mathrm{CO} ; 2$.

Hu, S., and A. V. Fedorov, 2017: The extreme El Niño of 2015-2016 and the end of global warming hiatus. Geophys. Res. Lett., 44, 3816-3824, https://doi.org/10.1002/2017GL072908.

Kim, Y.-H., and H.-Y. Chun, 2015: Momentum forcing of the quasi-biennial oscillation by equatorial waves in recent reanalyses. Atmos. Phys. Chem., 15, 6577-6587, https://doi.org/ 10.5194/acp-15-6577-2015.

Magnusdottir, G., and P. H. Haynes, 1999: Reflection of planetary waves in three-dimension tropospheric flows. J. Atmos. Sci., 56, 652-670, https://doi.org/10.1175/1520-0469(1999)056<0652: ROPWIT>2.0.CO;2.

Matsuno, T., 1966: Quasi-geostrophic motions in the equatorial area. J. Meteor. Soc. Japan, 44, 25-43, https://doi.org/10.2151/ jmsj1965.44.1_25.

Newman, P. A., L. Coy, S. Pawson, and L. R. Lait, 2016: The anomalous change in the QBO in 2015-2016. Geophys. Res. Lett., 43, 8791-8797, https://doi.org/10.1002/2016GL070373.

Osprey, S. M., N. Butchart, J. R. Knight, A. A. Scaife, K. Hamilton, J. A. Anstey, V. Schenzinger, and C. Zhang, 2016: An unexpected disruption of the atmospheric quasi-biennial oscillation. Science, 353, 1424-1427, https://doi.org/10.1126/science.aah4156.

O'Sullivan, D., 1997: Interaction of extratropical Rossby waves with westerly quasi-biennial oscillation winds. J. Geophys. Res., 102, 19461-19 469, https://doi.org/10.1029/97JD01524.

Randel, W. J., and I. M. Held, 1991: Phase speed spectra of transient eddy fluxes and critical layer absorption. J. Atmos. Sci. 48, 688-697, https://doi.org/10.1175/1520-0469(1991)048<0688: PSSOTE $>2.0 . \mathrm{CO} ; 2$.

Santoso, A., M. J. McPhaden, and W. Cai, 2017: The defining characteristics of ENSO extremes and the strong 2015/2016 El Niño. Rev. Geophys., 55, 1079-1129, https://doi.org/10.1002/ 2017RG000560.

Tweedy, O. V., and Coauthors, 2017: Response of trace gases to the disrupted 2015-2016 quasi-biennial oscillation. Atmos. Phys. Chem., 17, 6813-6823, https://doi.org/10.5194/acp-17-6813-2017.

von Storch, H., and F. W. Zwiers, 1999: Statistical Analysis in Climate Research. Cambridge University Press, 484 pp.

Wallace, J. M., R. L. Panetta, and J. Estberg, 1993: Representation of the equatorial stratospheric quasi-biennial oscillation in EOF phase space. J. Atmos. Sci., 50, 1751-1762, https://doi.org/ 10.1175/1520-0469(1993)050<1751:ROTESQ > 2.0.CO;2.

Watanabe, S., K. Hamilton, S. Osprey, Y. Kawatani, and E. Nishimoto, 2018: First successful hindcast of the 2016 disruption of the stratospheric quasi-biennial oscillation. Geophys. Res. Lett., 45, 1602-1610, https://doi.org/10.1002/ 2017 GL076406.

Waugh, D. W., L. M. Polvani, and R. A. Plumb, 1994: Nonlinear, barotropic response to a localized topographic forcing: Formation of a "tropical surf zone" and its effect on interhemispheric propagation. J. Atmos. Sci., 51, 1401-1416, https:// doi.org/10.1175/1520-0469(1994)051<1401:NBRTAL > 2.0.CO;2

Wheeler, M., and G. N. Kiladis, 1999: Convectively coupled equatorial waves: Analysis of clouds and temperature in the wavenumber-frequency domain. J. Atmos. Sci., 56, 374-399, https://doi.org/10.1175/1520-0469(1999)056<0374:CCEWAO > 2.0.CO;2. 